\title{
Multicultural Issues in Supervision - Supervising International Counseling Students
}

\author{
Adekemi Ekanoye \\ Department of Counseling Education and Supervision, Faculty of Liberal Art, Education and Human Development, University of New \\ Orleans, Louisiana, USA \\ Email address: \\ adekemi.ekanoye09@gmail.com \\ To cite this article: \\ Adekemi Ekanoye. Multicultural Issues in Supervision - Supervising International Counseling Students. Psychology and Behavioral \\ Sciences. Vol. 9, No. 2, 2020, pp. 12-26. doi: 10.11648/j.pbs.20200902.12
}

Received: April 21, 2020; Accepted: May 15, 2020; Published: May 27, 2020

\begin{abstract}
America has become a multi-cultural society, hence international students who have chosen a career in counseling education have increasingly embraced the United States as a destination for their studies most especially at the graduate level. According to a survey of CACREP-accredited counseling programs in the U.S. conducted by Ng in 2006 stated that 24 out of 45 doctoral programs had 77 international students in total enrolled in 2004, which was an average of three students per program. Unique challenges and difficulties are faced by these international students during their studies and training in the counseling and supervision program. Some of the challenges faced by the students are communication during i.e language barrier and getting counseling agency sites for their practicum and internship aspect of their study. Acculturation is another problem that students face. Students leave their country of origin and are subjected to transitioning process into new culture which sometimes become difficult to integrate. This cross-cultural experience transitions into the supervisory relationship. Supervisors have to be competent in understanding the various dynamics that are paramount to relating with international students. Knowing the challenges that the students face provides an effective platform to bridge the gap between the student (supervisee) and the supervisor.
\end{abstract}

Keywords: Counseling, Supervision, Multi-cultural

\section{Introduction}

Some of the unique challenges and difficulties faced are: Proficiency of English limitation, Understanding the culture of America, discriminatory attitudes from clients, supervisors, instructors, and peers in academic and clinical settings. $[15,16]$. Counseling and supervision require high level of interpersonal skill with utmost sensitivity [7, 18]. A supervisor that shows unresponsiveness or blindness to the supervision needs of the international trainee could impede the professional experience of such student. According to Killian [11] international trainees experience discomfort and tension in the cross-cultural supervisory relationships, when American supervisors and fellow supervisees fail to recognize culture of origin differences and even feel burdened having them in the supervision group.

Personally and professionally, supervision is essential to counselors' development. This is the foundation to counselor's competence in ensuring that clients' welfare are monitored through quality professional services rendering [2]. Understanding, trust and support are promoted when a functional relationship is built in the course of supervisor and supervisee training, on the flip side, a nonfunctional relationship between the supervisor and the supervisee can be a source of confusion, conflict, and misunderstanding. As quoted by D'Andrea \& Daniels [5], “Conflict in supervision happens when the supervisor and supervisee are not able to communicate their needs and concerns to one another".

It is important that cross-cultural issues are discussed during supervision in counseling education. This can assist in averting issues that may arise as a result of differences in ethnicity, language, age, gender, sexual orientation, socioeconomic status, spirituality belief, or ableness.

Several research studies have identified multiculturalism or diversity in supervision as a potential issue influencing supervisory relationships $[2,4,5,21]$. An empirical study carried out by Constantine [4] among predoctoral interns and their supervisors showed that $15 \%$ of the time was devoted 
on multicultural issue during supervision.

Participants involved in the research were of the opinion that more time ought to have been expended on multicultural issues for the research to be beneficial for them. In an event that the supervisor refuses to initiate, explore, or discuss cultural issues in supervision, the resultant effect will always be miscommunications, misunderstandings, hidden agendas, assumptions, and disconnections between the supervisors and supervisee. In as much as the counseling profession has continuously built literature that are in tandem with the international counselor-in-training needs and experiences in training, rigorous qualitative studies are still needed that examine supervisees' experiences in multicultural supervision [8].

\section{Critical Questions About the Topic}

The research publication by Jang et al. [10] used a consensual qualitative research methodology, to examine the difficulties doctoral-level international students encountered in counselor education programs and during supervisor training. A semi- structure interview format was administered with eight participants to critically ask what leads to negative experiences for this group of individuals. The research revealed that lack of discussion on culture and diversity in the class and the absence of multicultural supervision models, with unsupportive peers and course instructors as the most challenging parts of their supervision training.

The research conducted by Sangganjanavanich and Black [24] used phenomenological examination to determine the supervisory needs, experiences, attitudes, and perceptions of international counselors-in training during their first practicum. The research sought to ask the critical question that borders on the causes of supervisor insensitivity, interpersonal isolation, inter-cultural confusion and stereotyping. Lack of cultural sensitivity by a supervisor as well as his/her failure to provide honest feedback causes frustration and disappointment for international counselorsin-training.

A study carried out by Li [4] highlighted the plights, challenges and hardships of international doctoral students in the process of discipline enculturation. The study sought to ask the critical question about the acculturation problems faced by non-English speaking background (NESB) international student. An argument in the literature states that "the dynamic interplay of the dichotomy fosters students' intercultural competence, critical thinking, research skills, independence, and academic scholarships, and prepares the students for new challenges and multiple academic demands.

The critical question asked on the research conducted by Blount and Mullen [3] is on the issue of wellness in the counseling profession. Wellness is referred to as the cornerstone of the counseling profession. Apparently literatures on supervision contain few models that have a wellness focus or component. Counselors with poor wellness may not produce optimal services for the clients they serve
[12]. It is of importance that the introduction of integrative wellness model is inculcated in existing supervision models, whilst matching the developmental needs of counselors-intraining and theoretical tenets of wellness.

The research by Park et al [20] revealed fear that stemmed from language barrier and/or a lack of understanding of the American counseling system by the international student as the primary issue. The critical questions of providing practical information such as sites, the American counseling system, insurance, and cultures, in addition to ensuring that supervisors and faculty members increase in multicultural competency and sensitivity about international students provides the phenomenological research grounds for findings that emerged from the study.

In the research literature by Illan et al. [9], the critical question on the topic borders on perceptions and experiences of international counseling students (ICSs) in university training programs in Turkey. The students experienced problems relating to language, food, and customs. The literature showed that course work and applied experiences have become the desire of many students. The study also showed that many students surveyed thought that they would not return to their home countries because of job opportunity problems due to their ability to adapt in Turkey. Another critical question from this literature is how opportunities are created for international students in counseling education as a result of "the indigenization of the counseling profession in local settings and discovering the culture-specific elements that are central to practice in one's own region" [13].

\subsection{A Critique of the Literature Reviewed, (What Research Said About the Issue - What are the Gaps?)}

The study identified the increasing embrace of international experiences for students who have decided to seek training outside their own countries. The result of the study conducted by Illan et al. [9] could not be generalized because it made use of semi structured format and only relied on responses from 20 participants, hence making the finding to be limited. A larger sample size of international students would have been used which will give a more generalized result. Varied qualitative case study approach would have been employed which would have shed more light on the topic. The study did not mention the impact of a longitudinal study which can be used to track the training and performances of the international student overtime.

The research carried out by Park et al [20] focused on experiences of international students, most especially $\mathrm{PhD}$ students during practicum and internship. The essence is for the students to be able to apply the theories and the counseling development skills learned to help those in need. However, the study did not mention a systematic support procedure that can help in improving the experiences of the international student neither did it provide a practical information about internship/practicum sites, in-depth knowledge about the counseling system in America and the how the America culture can be understood.

The research literature by Blount and Mullen [3] had 
wellness component as the core factor in supervision, however the model does not show to be beneficial to advanced counselors who have already mapped out wellness strategy in conducting supervision. The model also does not show to be effective across multicultural groups (i.e., races, ethnicities, genders, religion) because the literature does not show an adherence to holistic paradigm of wellness construct.

The research conducted by $\mathrm{Li}$ [14] had relatively small sample to draw inference. The gravity and magnitude of the issues in supervisory practices for international students in New Zealand universities could not be examined properly as a result of the sample size used. The research did not highlight how the doctoral students benefited in terms of addressing their needs. Focus was heavy on the language skills development of the student, which did not prove to be helpful because other important aspect were neglected, like their writing skills, mastering of discipline and genre discourses, and articulation and development of the concepts, ideas, and theories, more than linguistic features.

The literature in the research by Sangganjanavanich and Black [24], the phenomenological small sample size was not sufficient for generalization of all international counselor-intraining. Additionally, the literature lacks the effective training modality for international counselors-in-training and the critical examination of acculturation experience of international counselors-in-training which is paramount to obtaining an understanding of the cultural adjustment of international counselor-in-training.

Jang et al. [10] in their research did not highlight whether the participants' responses are indicative of other International supervision trainees experiences, this therefore made the research findings to be perceived as a glimpse into the lives of a certain participants and not generalizable. Also because some students do not experience difficulties like others during supervisor training, most likely, chose not to participate in the study, hence the thematic components that emerged from this study was not replicated with those unaffected students.

\subsection{Implications for the Practice of Supervision}

Inclusion of the practical elements in training of international student is very important most especially at the introductory level. In comparison with their United States counterparts, international students tend to spend more time outside the classroom, trying to understand the contents of the course because of language and the issue of culture. The desire to develop fast-paced training especially to carter for the needs of the international students is paramount and this can achieved when instructors have a clear delineation in supervision courses, as well as an additional lab for this purpose. This approach will be valuable in allowing ISTs to better contextualize and visualize counseling supervision, with the additional added benefit of processing supervisors' rationales undergirding their actions during supervision sessions [10].

Multicultural competencies extends the work of the supervisors in handling culturally diverse international counselors-in-training. Skills, attitudes, and knowledge related to international student are monitored. This monitoring can include an awareness of the dynamics of power, privilege, and acculturation [24]. It is of immense importance that Supervisors seek multicultural training to ensure they have basic knowledge about multicultural concerns and diversity. In achieving meaningful and effective supervisory relationships, supervisors must be authentic, transparent and accountable enough to act ss role models for international students. Further to building effective relationship between the supervisor and the international counselor-in-training, supervisors can invite international counselors-in-training to educate them about their specific cultural backgrounds/beliefs and remain open to the cultural variations expressed by the student [24].

International students feel more engaged when their perception are recognized and not just voice of culture. They feel more relaxed with their American peers when they discuss their similarities and difference between and among their cultures. Exposing international students to American culture can be achieved by supervisor in a way of creating opportunities to promote understanding of social interaction, expectations, values, and beliefs. This type of social interaction can take the form of formal or informal contacts, discussing current events as well as movies and other media.

As asserted by Roach and Young [22], a supervision model that incorporates wellness is a logical fit in counseling and counselor education, where programs can and should address personal development through wellness strategies for Counselor in-training. Wellness cannot be overemphasized because counselor-in-training often show higher disturbances when the issue of wellness is not taking into consideration. Theory and history of wellness in counseling are core to the profession but often time, the counselor and the counselor-intraining fail to take their own wellness seriously. The implementation of a model like the Integrative Wellness Model (IWS) by Roach and Young [22] can aid in supporting overall wellness in supervisees as well as educating Counselor-In-Training to practice wellness with their clients and with themselves.

Park et al. [20] expressed that the major implication of this study is to gain better understanding of international students in counseling education and also having real experiences of international trainees regarding practica/internships, which may contribute to increasing counselor educators' multicultural awareness and understanding. The level of English proficiency and understanding of American culture have been the greatest challenge that international student face, but however in some ramifications, programs and site participants have been supportive in crafting developmental paths called counseling self-efficacy, which appear to put the positive initiative on the right track. In increasing the readiness of international students in the counselor education program, there is need to provide a systematic support in helping 
them.

\section{Multicultural/Social Justice Considerations (Does the Literature Speak to These)}

Although the selected literatures for this study did not mention the social justice consideration of counseling education as it relates to international student in-training, but generally, master's and doctoral level students are trained to become leaders in the counseling field by developing competencies in the areas of multiculturalism, social justice, advocacy, and global mindedness [1]. International students are from various parts of the world and hence come to the United States with multiple culture. There has been a growing need to increase and accommodate diversity in the Western societies, as a result, most counselor education programs continue to use traditional counselor training models that are based on European American norms [26].

Counselors and psychologists are uniquely positioned to address social justice issues based on the profession's emphasis on prevention, strength based approaches, and multiculturalism [6]. Faculties need to continuously discuss ways of developing and establishing counseling programs with multicultural social justice components. Some specific strategies that could encourage the development of social justice agenda within counseling program which international student counselor-in-training can benefits from are thus:

1. Faculties can hold retreats in generating consensus on defining and refining what multicultural social justice counseling mean.

2. Promotion of commonly agreed definition of multicultural social justice throughout course curriculum by the faculties.

3. Faculties can create a forum of applying multicultural social justice discussion on topics that are taught in the classroom

4. By discussing personal biases regarding the race, gender, privilege, oppression etc.

\section{Conclusion}

The study advises supervisors to raise their awareness as it pertains to culture and be sensitive with international trainees. International trainees' development and supervision process can be positively influenced when supervisors support them in the self-disclosure of their perceived cultural barriers in counseling and supervision sessions. Working with international trainees requires that supervisors explore their own reaction [17]. This is achieved when the supervisors become aware of their own biases and assumptions related to international trainees, supervisors can assess their comfort and sensitivity in being able to work with international trainees [17].

In the nut shell, supervisors have to become more culturally competent and culturally sensitive by extending an expanding their knowledge base of training internationals at acculturation level and how this may influence specific trainee needs in supervision, this can be termed as "structure supervision" of clinical work and "understanding racial dynamics". Mindfulness of supervisors of acculturation level during cultural discussion with trainees should be taken into consideration due to impact on both supervision and clinical experiences. Prejudice may inhibit international trainees from seeking help, hence supervisors may also need to engage in systemic advocacy to reduce potential attrition of clients due to biases inherent at different levels (e.g., clients, administration).

\section{References}

[1] Bemack, F., Talleyrand, R. M., Jones, H., \& Daquin, J. (2011). Implementing multicultural social justice strategies in counselor education training programs. Journal for Social Action in Counseling \& Psychology, 3 (1), 29-43.

[2] Bernard, J. M., \& Goodyear, R. K. (2009). Fundamentals of clinical supervision (4th ed.). Boston: Allyn and Bacon.

[3] Blount, A. J., \& Mullen, P. R. (2015). Development of an integrative wellness model: Supervising counselors-intraining. The Professional Counselor, 5 (1), 100.

[4] Constantine, M. G. (1997). Facilitating multicultural competency in counseling supervision: Operationalizing a practical framework. In D. B. Pope-Davis \& H. L. K. Coleman (Eds.), Multicultural counseling competencies: Assessment, education and training, and supervision (pp. 310324). Thousand Oaks, CA: Sage.

[5] D’Andrea, M., \& Daniels, J. (1997). Multicultural counseling supervision: Central issues, theoretical considerations, and practical strategies. In D. B. Pope-Davis \& H. L. K. Coleman (Eds.), Multicultural competencies: Assessment, education, and training, and supervision (pp. 290-309). Thousand Oaks, CA: Sage.

[6] Fouad, N. A., Gerstein, L. H., \& Toporek, R. L. (2006). Social justice and counseling psychology in context. In R. L. Toporek, L. Gerstein, N. Fouad, G. Roysircar, and T. Israel (Eds.), Handbook for social justice in counseling psychology: Leadership, vision, and action (pp. 1-16). Thousand Oaks, CA: Sage.

[7] Garrett, M. T., Borders, L. D., Crutchfield, L. B., TorresRivera, E., Brotherton, D., \& Curtis, R. (2001). Multicultural supervision: A paradigm of cultural responsiveness for supervisors. Journal of Multicultural Counseling and Development, 29, 147-158.

[8] Hird, J. S., Cavalieri, C. E., Dulko, J. P., Felice, A. A. D., \& Ho, T. A. (2001). Vision and trc5f4realities: Supervisee perspectives of multicultural supervision. Journal of Multicultural Counseling and Development, 29, 114-130.

[9] Ilhan, T., Korkut-Owen, F., Furr, S., \& Parikh, S. (2012). International counseling students in Turkey and their training experiences. International Journal for the Advancement of Counselling, 34 (1), 55-71.

[10] Jang, Y. J., Woo, H., \& Henfield, M. S. (2014). A qualitative study of challenges faced by international doctoral students in counselor education supervision courses. Asia Pacific Education Review, 15 (4), 561-572. 
[11] Killian, K. D. (2001). Differences making a difference: Crosscultural interactions in supervisory relationships. Journal of Feminist Family Therapy, 12, 61-103.

[12] Lawson, G. (2007). Counselor wellness and impairment: A national survey. The Journal of Humanistic Counseling, Education and Development, 46, 20-34.

[13] Leung, S. M., Clawson, T., Norsworthy, K., Tena, A., Szilagyi, A., \& Rogers, J. (2009). Internationalization of the counseling profession. In L. H. Gerstein, P. Heppner, S. Ægisdóttir, S.-M. Leung, \& K. L. Norsworthy (Eds.), International handbook of cross-cultural counseling (pp. 111-123). Thousand Oaks: SAGE Publications, Inc.

[14] Li, M. (2012). Developing Skills and Disposition for Lifelong Learning: Acculturative Issues 6XUURXQGLQJ Supervising International Doctoral 6WXGHQWV LQ New Zealand Universities. Journal of International Students 2016 Vol 6 Issue 3, 6 (3), 740-761.

[15] Ng, K. M. (2006). International students in CACREPaccredited counseling programs. Journal of Professional Counseling: Practice, Theory, and Research, 34, 20-32.

[16] Mittal, M., \& Wieling, E. (2006). Training experiences of international doctoral students in marriage and family therapy. Journal of Marital and Family Therapy, 32, 369-383.

[17] Mori, Y., Inman, A. G., \& Caskie, G. I. (2009). Supervising international students: Relationship between acculturation, supervisor multicultural competence, cultural discussions, and supervision satisfaction. Training and Education in Professional Psychology, 3 (1), 10.

[18] Nilsson, J. E., \& Anderson, M. Z. (2004). Supervising international students: The role of acculturation, role ambiguity, and multicultural discussions. Professional Psychology: Research and Practice, 35, 306-312.
[19] Nilsson, J. E., \& Dodds, A. K. (2006). A pilot phase in the development of the International Student Supervision Scale. Journal of Multicultural Counseling and Development, 34, $50-62$.

[20] Park, S., Lee, J. H., \& Wood, S. M. (2017). Experiences of international students in practicum and internship courses: A consensus qualitative research. The Journal of Counselor Preparation and Supervision, 9 (2), 5.

[21] Pope-Davis, D. B, Toporek, R. L., \& Ortega-Villalobos, L. (2003). Assessing supervisors' and supervisees' perceptions of multicultural competence in supervision using the multicultural supervision inventory. In D. B. Pope-Davis (Eds.) (2003). Handbook of multicultural competencies in counseling and psychology (pp. 211-224). Thousand Oaks, CA: Sage.

[22] Roach, L. F., \& Young, M. E. (2007). Do counselor education programs promote wellness in their students? Counselor.

[23] Education and Supervision, 47, 29-45. doi: 10.1002/j.15566978.2007.tb00036.x.

[24] Sangganjanavanich, V. F., \& Black, L. L. (2009). Clinical supervision for international counselors-in-training: Implications for supervisors. Journal of Professional Counseling: Practice, Theory \& Research, 37 (2), 52-65.

[25] Smith, S. D., \& Ng, K. M. (2009). International counseling trainees' experiences and perceptions of their multicultural counseling training in the United States: A mixed method inquiry. International Journal for the Advancement of Counselling, 31, 271-285.

[26] Zalaquett, C. P., Foley, P. F., Tillotson, K., Dinsmore, J. A., \& Hof, D. (2008). Multicultural and social justice training for Counselor Education Programs and Colleges of Education: Rewards and challenges. Journal of Counseling and Development, 86, 323-329. 